\title{
Closed Die Forging of Mg-Al-Zn-Ca-Y Alloys
}

\author{
Nikolaus Papenberg ${ }^{1, a *}$ and Stefan Gneiger ${ }^{1, b}$ \\ ${ }^{1}$ LKR Light Metals Technologies Ranshofen GmbH, Lamprechtshausenerstraße 61, 5282 \\ Ranshofen, Austria \\ anikolaus.papenberg@ait.ac.at, bstefan.gneiger@ait.ac.at
}

Keywords: Mg-Al-Zn-Ca-Y alloys, AZXW alloys, closed die forging, magnesium, AZ31

\begin{abstract}
In light of emission reduction and weight saving in transport applications, $\mathrm{Mg}$ parts gain a lot attention due to their good specific mechanical properties and their low mass. While casting is the main process for manufacturing Mg parts for automotive applications, forged parts show some major benefits like superior mechanical properties and absence of porosity. In this work a comparison of closed die forged parts made from different Mg-alloys has been carried out. The materials used in the warm forging process were AZ31 and various Mg-Al-Zn-Ca-Y type (AZXW) alloys. Ca additions are known to improve the oxidation behaviour and the formability of magnesium alloys, while yttrium is used to enhance the flammability resistance of forged parts. The forgeability, mechanical properties and microstructure are analyzed and compared in the present paper.
\end{abstract}

\section{Introduction}

Magnesium is the lightest of all construction metals and magnesium alloys possess a high strengthto-weight ratio, making them a lighter alternative in applications where minimal mass is preferred over minimal costs. Although weight is an important factor in almost every vehicle within the whole field of transportation, it is crucial for aircraft manufacturers and airlines. While an early pay-off during aircraft operation can be reached from an ecological point of view, in terms of costs the use of $\mathrm{Mg}$ parts is not always justified. Based on a life cycle assessment initiated by the International Magnesium Association [1], only a few flights with an Airbus A320 over a distance of $4.100 \mathrm{~km}$ are necessary for reaching the ecological break-even point for the amortization of higher emissions during component production. According to a life cycle assessment carried out by Recaro [2], the break-evenpoint in terms of costs for substitution of one selected seat component is achieved only after two years. In addition, sinking fuel share of total operating costs in recent years due to more efficient engines and aerodynamics worsen the perspective of an economical $\mathrm{Mg}$ usage even further. Nevertheless, significantly increasing air traffic [3], in combination with the aim to halve carbon emissions caused by aviation till 2050 [4] and the therefore necessary weight reductions led to a rethinking of $\mathrm{Mg}$ as engineering material.

Although magnesium has been used in aircraft engine parts for more than 70 years and is still in use in engine parts of almost every modern aircraft [5], magnesium inside of passenger airplanes was prohibited for many years. Recent efforts led to an easing of this ban by the end of 2015 and now the use of magnesium for aircraft seats is allowed under the condition that the materials pass a specific flammability test [6].

Since then, several efforts were made to develop magnesium alloys able to fulfil the flammability requirements requested by the FAA (Federal Aviation Administration). While alloys containing large amounts of rare earths e.g. WE43 and Elektron 21 are able to pass this test, cost efficient alternatives are demanded. This led to the development of Mg-Al-Ca alloys, which are relying on the flame retardant effect of calcium generated by the formation of additional oxide layers [7, 8, 9]. These alloys are substantially cheaper than other well performing alloys and can be manufactured with conventional processing routes like high pressure die casting and extrusion. Additionally, Ca reduces the reactivity of magnesium melt which makes melt handling safer and less complex. Ca containing alloys are less prone to self-ignition at higher temperatures e.g. during heat treatment, which enables processing without the use of environmental harmful and strictly regulated [10] fluoride gases. 
Many of the considered parts in the aircraft interior are produced by extrusion and forging [11], which offer improved mechanical properties when compared to cast parts [12]. Forming of Mg-alloys is in generally a difficult process, being owed to necessary high specific temperatures, low forming speeds and anisotropic material behaviour which cause narrow processing windows. A thorough understanding of all forming and heat treatment steps [13] in relation to the formed part [14] is necessary. In general, forging temperatures should be chosen as low as practically possible to take advantage of the increase in mechanical properties (i.e. strain hardening) achieved by forming [15]. While AZ31 probably is the most frequently studied alloy in $\mathrm{Mg}$ forming, some studies of Ca containing $\mathrm{Mg}$ alloys have already been done with varying alloy compositions, stock materials and forging processes. Harandi et al. [16] examined the hot forming and originating corrosion behaviour of a $\mathrm{Mg}-1 \mathrm{Ca}$ alloy. They concluded that higher hardness can be achieved by higher forging temperatures because of the precipitation of the $\mathrm{Mg}_{2} \mathrm{Ca}$-Phase. Several publications deal with the increasing creep performance of AZX alloys caused by the formation of $\mathrm{Al}_{2} \mathrm{Ca}$ and $\mathrm{Mg}_{2} \mathrm{Ca}$. In their investigations of AZX312, Suresh et al. [17] found $425-450{ }^{\circ} \mathrm{C}$ and $0.001-0.01 \mathrm{~s}^{-1}$ to be the best isothermal forging parameters for cast stock material.

While the understanding of these Ca containing alloys, in terms of oxidation and casting behaviour, has vastly increased in the recent years $[18,19,20]$, their forming capabilities on the other hand have not yet been in the focus of intense investigations. Those investigations are necessary if this promising alloy system is to be employed in industrial applications. Therefore this paper will study the influence of $\mathrm{Ca}$ on the closed die forging process and the resulting microstructural and mechanical properties.

\section{Material and Methods}

All materials were cast, machined, formed, heat treated and tested at LKR Ranshofen with exception of the wet chemical analysis which has been done externally.

Material. Four Mg-Al-Zn based alloys were prepared using commercial Mg ingot (99.8 wt. \%), Al ingot (99.9 wt. \%), Zn ingot (99.8 wt. \%), Ca granules (99.6 wt. \%), manganese chloride and a commercial Mg-30 wt. \% Y master alloy. The exact chemical compositions measured by ICP-OES are given in Table 1. The manganese content of the AZXW alloys was kept low in order to avoid undesired AlMn-Y phases. Billets with a diameter of $63 \mathrm{~mm}$ and a length of $240 \mathrm{~mm}$ were cast in a preheated steel mold and subsequently machined to forging billets with diameter $22 \mathrm{~mm}$ and a length of $150 \mathrm{~mm}$. The billets were homogenized for 24 hours at $415^{\circ} \mathrm{C}$ and cooled by forced convection.

Table 1. Chemical composition of the cast alloys in wt. \%

\begin{tabular}{|l|c|c|c|c|c|c|}
\hline & $\mathrm{Al}$ & $\mathrm{Zn}$ & $\mathrm{Mn}$ & $\mathrm{Ca}$ & $\mathrm{Y}$ & $\mathrm{Mg}$ \\
\hline AZ31B & 2.95 & 0.96 & 0.28 & $<0.005$ & $<0.005$ & Rem. \\
\hline AZXW3100 & 3.05 & 1.01 & 0.01 & 0.25 & 0.21 & Rem. \\
\hline AZXW3110 & 2.98 & 0.86 & 0.03 & 1.04 & 0.23 & Rem. \\
\hline AZXW3120 & 3.15 & 0.87 & 0.03 & 2.5 & 0.28 & Rem. \\
\hline
\end{tabular}

Forging. A $160 \mathrm{t}$ (Neff DZP160) hydraulic press was used to produce a simplified piston rod in a two step closed die forging process. Stock material in form of round bars were heated up to $400{ }^{\circ} \mathrm{C}$ and forged with die temperatures of $220^{\circ} \mathrm{C}$, a water based graphite lubricant was used. After the second forging step, the rods were quenched in water and the flash was directly removed in an adjacent $100 \mathrm{t}$ press. The forging die can be seen in Figure 1a (with the first step on the left hand side) and a successfully forged piston rod in Figure 1b. After flash removal, the piston rods were heat treated at $350^{\circ} \mathrm{C}$ furnace temperature for $30 \mathrm{~min}$ in order to allow recrystallisation and to relieve stresses introduced by forming.

Testing. A Bähr $805 \mathrm{~A} / \mathrm{D}$ deformation dilatometer was used for compression testing of cylindrical specimens (diameter $6 \mathrm{~mm}$, height $10 \mathrm{~mm}$ ), which was done at $300^{\circ} \mathrm{C}, 350^{\circ} \mathrm{C}$ and $400^{\circ} \mathrm{C}$ with varying 


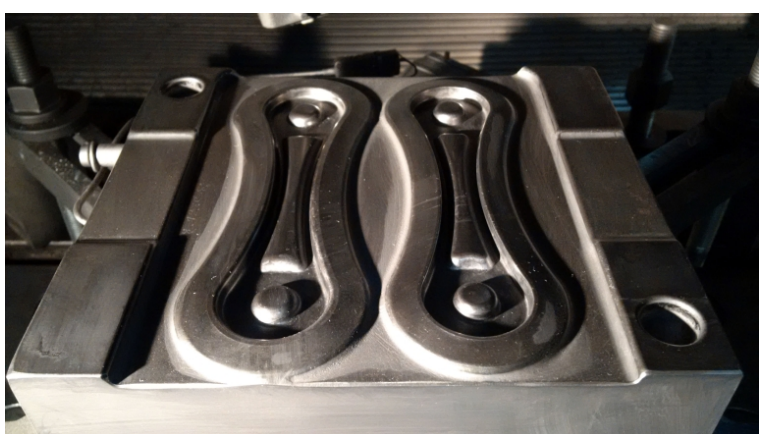

(a)

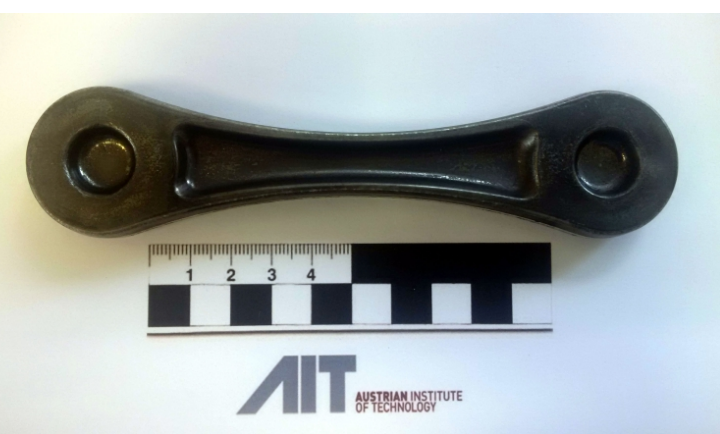

(b)

Fig. 1. (a) heatable two step forging die, (b) forged piston rod without flash

strain rates $\left(0.1-5 \mathrm{~s}^{-1}\right)$. Quasi-static tension testing was done on a Zwick Z250 at room temperature according to ÖNORM-EN-ISO 6892-1B, using flat $\left(\mathrm{L}_{0}=30 \mathrm{~mm}, \mathrm{~L}_{\mathrm{c}}=38 \mathrm{~mm}\right)$ specimen in as-forged and heat treated conditions.

The piston rods were cut apart in the centre and the resulting cross-sections were used for metallography and micro hardness testing. The surface was polished and the microstructure was investigated in a light microscope (Olympus BX60) before doing micro hardness testing with a LECO LM700. Subsequently, the samples were etched with picric acid containing solution to investigate the grain structure resulting from forging and subsequent heat treatment.

\section{Results and Discussion}

Dilatometer testing was carried out in the temperature range used in the forging process and the results are shown in Fig. 2. The well-known improvement of creep resistance and high temperature strength of Ca containing $\mathrm{Mg}$ alloys can be seen [17]. In this work the responsible intermetallic phases are $\mathrm{Al}_{2} \mathrm{Ca}$ (identified with EDX - data not shown). The peak flow stress of AZXW3120 at $300^{\circ} \mathrm{C}$ is $\sim 20 \mathrm{MPa}$ higher than AZ31. At higher temperatures, i.e. $400^{\circ} \mathrm{C}$, this effect is reduced significantly and the flow stresses of all alloys are nearly equal.
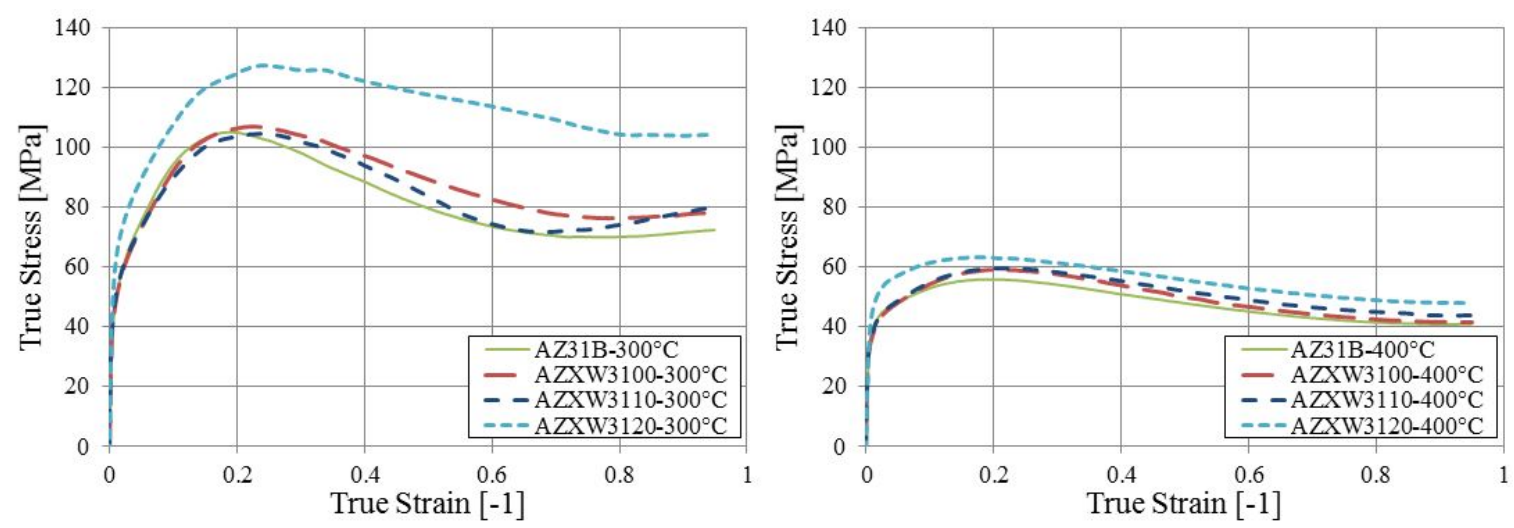

Fig. 2. Flow curves of all tested alloys at $300{ }^{\circ} \mathrm{C}$ and $400{ }^{\circ} \mathrm{C}$ with a strain rate of $0.1 \mathrm{~s}^{-1}$

The increase in flow stress was also noticeable in the forging process, were more force was necessary to form the AZXW3120 piston rods. The ductility of the material decreased with increasing Ca content, which was observable during removal of the forging flash and the shape of the flash itself. All parts could be formed successfully, but the forging flash of the AZXW3110 and 3120 alloys showed cracks on the outer edges. After flash removal at room temperature, the piston rods showed rough macroscopic fracture surfaces and sustained internal damage, as can be seen in Figure $3 \mathrm{~b}$.

While the amount of $\mathrm{Ca}$ containing phases on the grain boundaries and inside the grains increases with increasing $\mathrm{Ca}$ content, the microstructure created by forging is similar for all alloys. The grain 


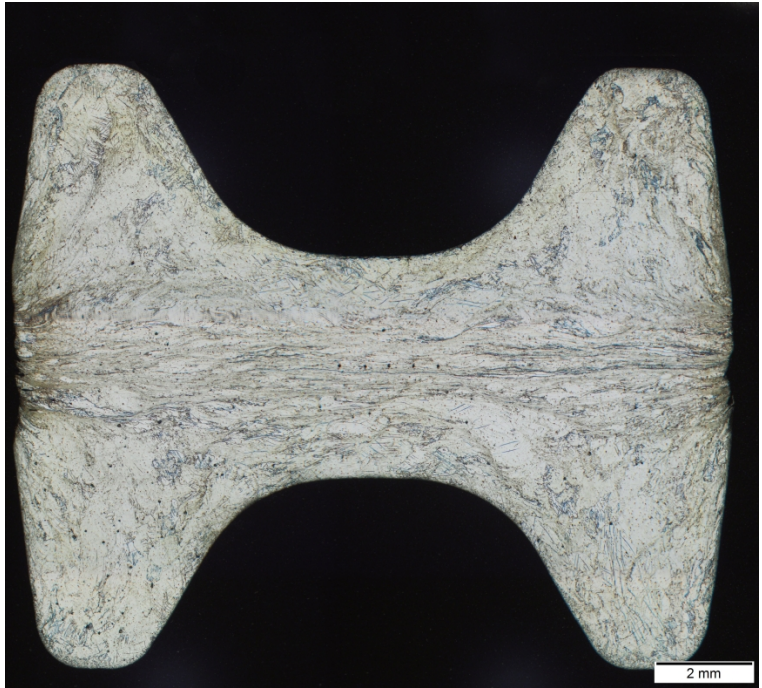

(a) AZXW3100

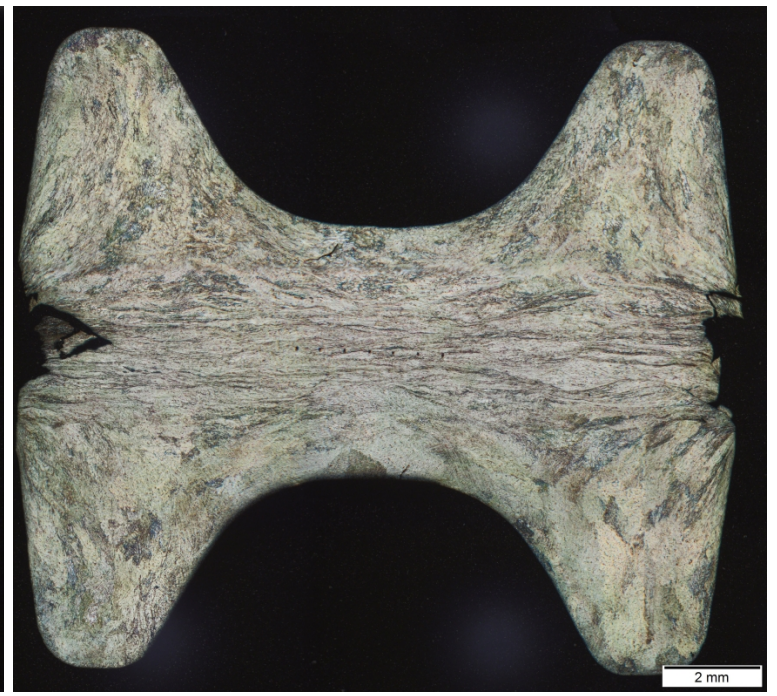

(b) AZXW3120

Fig. 3. Cross-sections of the piston rods etched with picric acid

structure within each piston rod changes depending on the degree of deformation, which varies from the outer edges towards the sample center. The center is dominated by fine recrystallized grains, often taking the form of a, for Mg alloys typical, necklace structure (Fig. 4a). Areas with less deformation still feature big grains pervaded with twins (Fig. 4b). After heat treatment the sample center shows a homogeneous microstructure of recrystallized grains (Fig. 4c) and the twins in the flange areas have nearly disappeared (Fig. 4d).

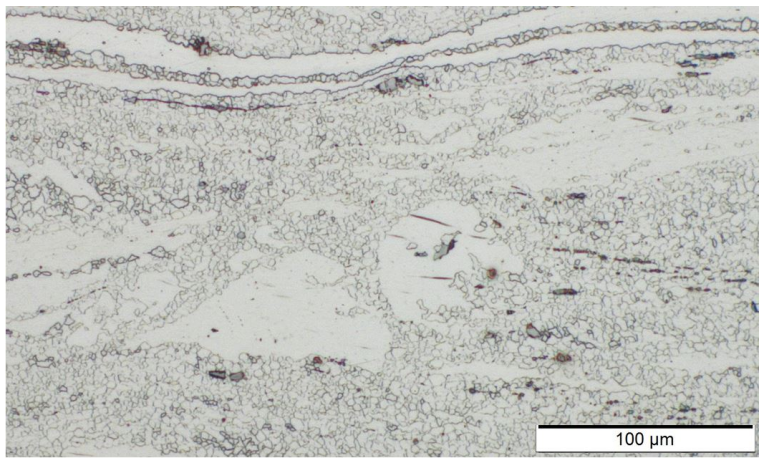

(a) as forged sample center

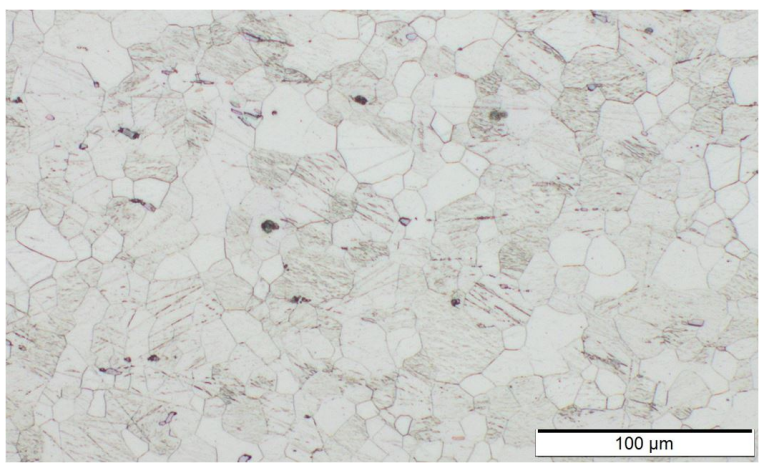

(c) heat treated sample center

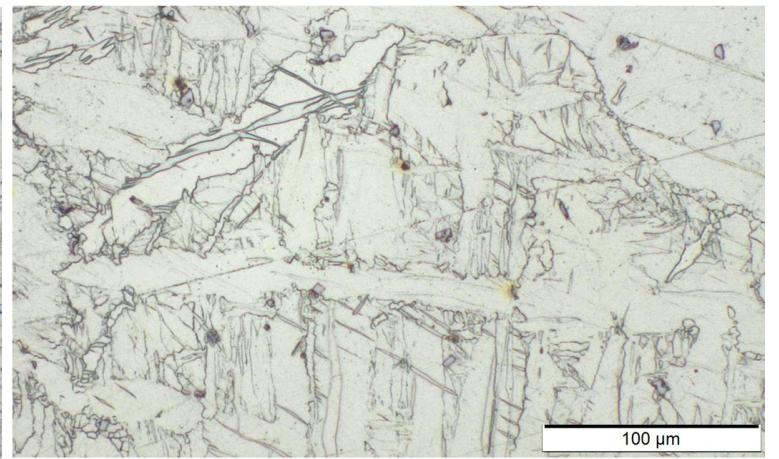

(b) as forged sample rim

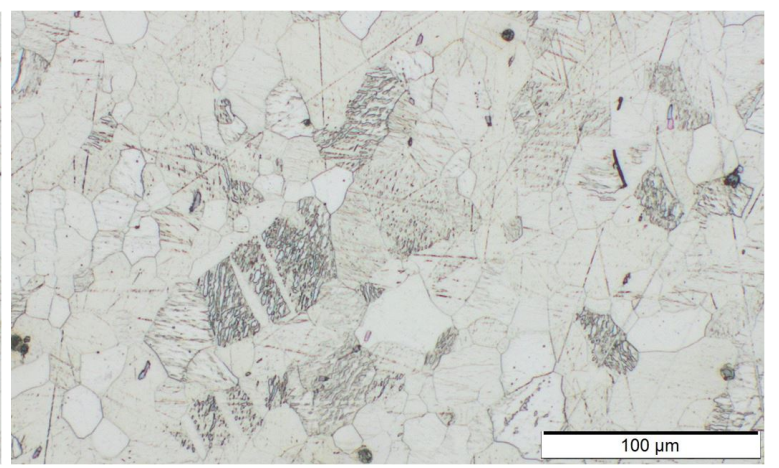

(d) heat treated sample rim

Fig. 4. Microstructure of AZXW3100 piston rods

The results from the tensile testing of the forged rods (Fig. 5) show an increase of yield strength with raising Ca content. While the tensile strength stays on the same level for all AZXW alloys, the 
uniform elongation decreases progressively. AZ31 shows the best overall tensile properties i.e. the highest tensile strength and elongation. The subsequent heat treatment decreased both tensile and yield strength for all alloys but drastically increased the elongation. AZ31 and AZXW3100 have comparable mechanical properties after heat treatment, showing the best tensile properties of the tested alloys.

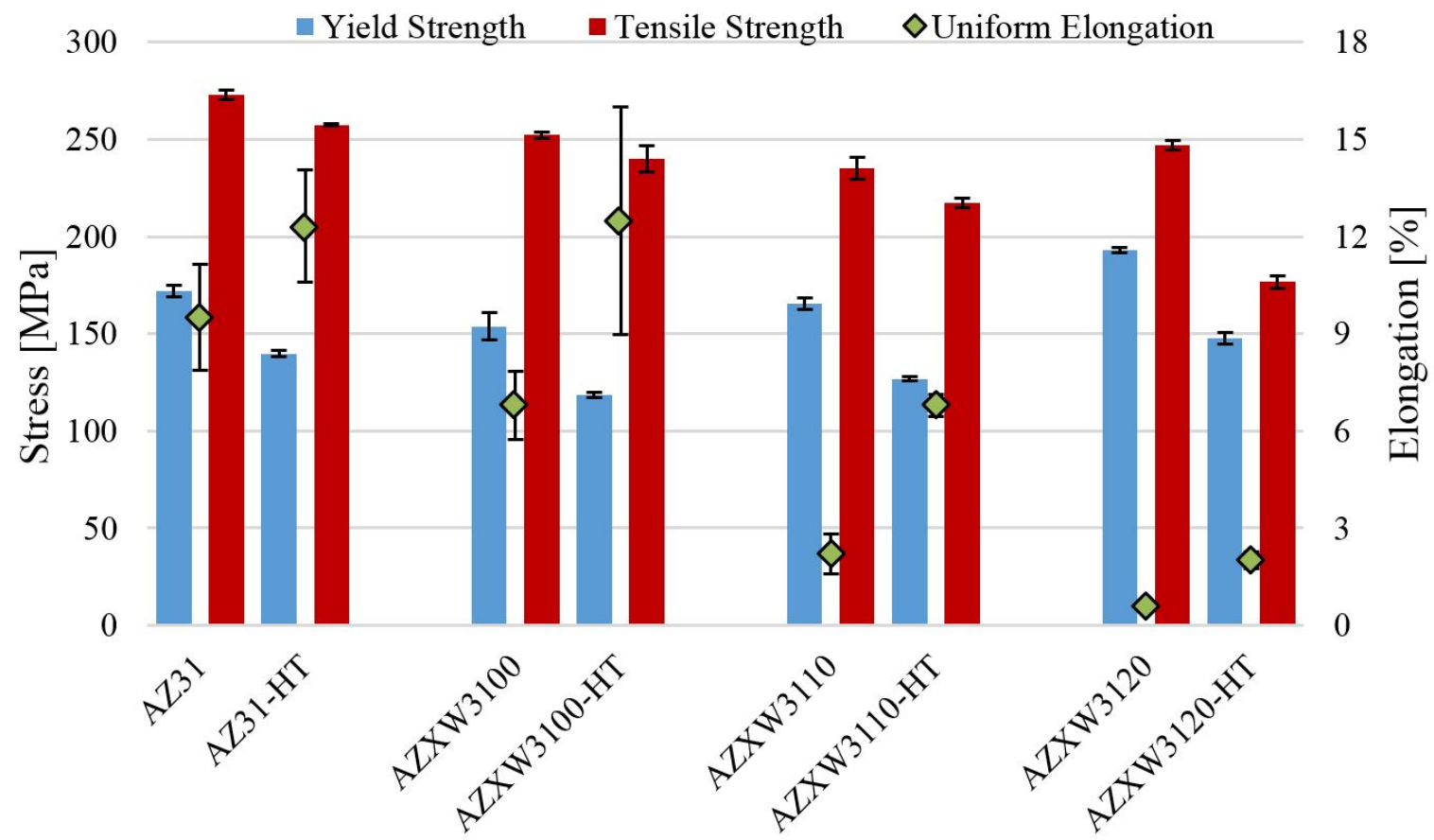

Fig. 5. Results from quasi-static tensile testing, comparing the forged and the heat treated (-HT) specimen. Standard deviation is shown by error bars

\section{Summary}

In this work an investigation of the processing parameters, microstructure and tensile properties of AZXW alloys in comparison to AZ31 has been done. It has been shown, that (1) a heat treatment of $360^{\circ} \mathrm{C}$ for $30 \mathrm{~min}$ considerably increases the elongation but only slightly reduces the tensile strength. (2) With increasing Ca content, the hardness and tensile strength increases slightly but the elongation declines sharply, (3) the tensile properties of AZ31 and AZXW3100 forged piston rods are comparable after heat treatment.

It can be concluded, that minor additions of $\mathrm{Ca}$ and $\mathrm{Y}$ to the classical AZ31 alloy, can be seen as an enhancement with the advantage of retarded flammability and better casting behaviour. While further research is needed, this is a promising step towards applying forged magnesium components in a wider field of applications.

\section{Acknowledgements}

The support for this work by the European Regional Development Fund (EFRE) in the framework of the EU-program "IWB Investition in Wachstum und Beschäftigung Österreich 2014-2020" and the federal state Upper Austria is gratefully acknowledged. 


\section{References}

[1] H. E. Friedrich and S. Ehrenberger, The IMA Study on the Life Cycle Assessment (LCA) of Magnesium, TMS 2014, Magnesium Technology 2014, p.13

[2] C. Hennrich, Magnesium in civil aviation cabin - Prospects \& Challenges, 25. Magnesium Abnehmer und Automotive Seminar 2017, Aalen

[3] Information on: http://www.airbus.com/content/dam/corporate-topics/publications/backgrounders/Airbus_Global_Market_Forecast_2017-2036_Growing_Horizons_full_book.pdf

[4] Information on http://www.atag.org/facts-and-figures.html

[5] B. Gwynne and P. Lyon, Magnesium Alloys in Aerospace Applications, Past Concerns, Current Solutions, Triennial International Aircraft Fire \& Cabin Safety Research Conference, Atlantic City, (2007)

[6] Information on http://standards.sae.org/wip/as8049c/

[7] S. Gneiger, R. Gradinger, C. Simson, Y. M. Kim, and B. S. Sun, Investigations on microstructure and mechanical properties of non-flammable Mg-Al-Zn-Ca-Y extruded alloys, 7th EUCASS, Milan, (2017)

[8] B.-S. You, W.-W. Park and I.-S. Chung, Effect of calcium additions on the oxidation behavior in magnesium alloys, Scr. Mater., vol. 42, no. 11 (2000), p.1089

[9] Y. Kim, H. Kim, B. You, and C. Yim, Patent CA2781995 A1 (2010)

[10] Information on https://ec.europa.eu/clima/policies/f-gas_en.

[11] A. Dziubinska, A. Gontarz, M, Dziubinski and M. Barszcz, The forming of magnesium alloy forgings for aircraft and automotive applications, Adv. Sci. Technol. Res. J. Vol. 10 (2016), p.158

[12] Y.M. Kim, B.S. You, M-S. Shim and N.J. Kim, Mechanical Properties and High-Temperature Oxidation Behavior of Mg-Al-Zn-Ca-Y Magnesium Alloys, TMS 2012, Magnesium Technology 2012, p.217

[13] M. Madaj, M. Greger and V. Karas, Magnesium-alloy die forgings for automotive applications, Materials and Technology MTAEC9 49 (2015) 2, p.267

[14] M. Graf, M. Ullmann and R. Kawalla, Property-oriented production of forged magnesium components, Mater. Today-Proc. 2S (2015), p.S76

[15] ASM International: Metals Handbook 9. Edition, Vol 14: Forming and Forging, 1988.

[16] S.E. Harandi, M.H. Idris and H. Jafari, Effect of forging process on microstructure, mechanical and corrosion properties of biodegradable Mg-1Ca alloy, Mater. Design 32 (2011), p.2596

[17] K. Suresh, K.P. Rao, Y.V.R.K. Prasad, N. Hort and K.U. Kainer, Study of hot forging behavior of as-cast Mg-3Al-1Zn-2Ca alloy towards optimization of its hot workability, Mater. Design 57 (2014), p.697

[18] B.-H. Choi, B.-S. You, W.-W. Park, Y.-B. Huang and I.-M. Park, Effect of Ca addition on the oxidation resistance of AZ91 magnesium alloys at elevated temperatures, Met. Mater. Int., vol. 9, no. 4 (2003), p.395

[19] Y.-I. Choi, K. Kuroda, and M. Okido, Temperature-dependent corrosion behaviour of flameresistant, Ca-containing AZX911 and AMX602 Mg alloys, Corros. Sci., vol. 103 (2016), p.181

[20] P. Li, B. Tang, and E. G. Kandalova, Microstructure and properties of AZ91D alloy with Ca additions, Mater. Lett., vol. 59, no. 6 (2005), p.671== 